\title{
Creutzfeldt-Jakob Disease Secondary to Dural Graft Performed in 1988
}

\author{
José Antonio Crespo-Burillo Natalia Hernando-Quintana Javier Marta-Moreno \\ Department of Neurology, Miguel Servet University Hospital, Zaragoza, Spain
}

Dear Sir,

Creutzfeldt-Jakob disease (CJD) is a neurodegenerative process produced by the deposition of a pathological isoform of a prion protein. There are three subtypes of CJD, broken down by etiology: sporadic (87\%), genetic (8\%), and acquired (5\%) [1]. The latter subtype includes variant CJD (vCJD) and iatrogenic CJD (iCJD). To date, over 400 cases of iCJD have been described in more than 20 countries $[2,3]$. Most reported cases were secondary to treatment with cadaveric human growth hormone or lyophilized cadaveric dura mater grafts [3]. Other, less frequent, sources of iCJD infections have included corneal transplants, electrodes used in stereotaxic electroencephalography, contaminated neurosurgical instruments, and transfusions of blood products [3].

The incidence of iCJD cases has decreased significantly in recent years thanks to the adoption of safety measures, and only isolated cases have been published in a few countries [3]. Six cases have been reported in Spain since 1993, when the National Spongiform Encephalopathy Registry was created by Instituto de Salud Carlos III (Madrid). All cases were caused by ly- ophilized dura mater grafts performed before 1989; the most recent case was published in 2004. In this report, we present the seventh and latest recorded case in Spain in the past 8 years [4].

\section{Case Report}

The patient was a 51-year-old male with a history of Arnold-Chiari I malformation and syringomyelia from $\mathrm{C} 1$ to T3. In October 1988, he was treated with laminectomy, amygdalectomy, and duraplasty. Gait alteration secondary to mild spastic paraparesis manifested as a long-term sequela.

In August 2012, the patient presented symptoms of altered behavior, including irritability, mood swings and apathy. $\mathrm{He}$ had been diagnosed with depressive syndrome several years earlier. His mirtazapine treatment had been suspended 1 month before that date, when he underwent shoulder arthroscopy. In mid-September of 2012, the patient first visited the emergency department due to symptom progression; he presented aggressiveness, difficulty planning activities of daily living, decreased attention span, and severe gait problems. These symptoms were evaluated by the psychiatric department, which initially attributed them to the withdrawal of antidepressant treatment. That treatment was therefore resumed and doctors recommended outpatient monitoring.

The patient's symptoms progressed to include poor personal hygiene, urinary incontinence, and progressive ataxia, and he was admitted to our hospital 15 days later. The initial examination confirmed cognitive impairment with frontoparietal predominance, alterations in executive and visuospatial functions, bilateral hand dystonia, choreoathetotic movements of the right arm and neck, and significant truncal ataxia for which the patient required bilateral walking support.

Brain MRI revealed increased signal intensity in diffusion-weighted sequences of cortical grey matter in the frontal region of both hemispheres (fig. 1). The electroencephalogram (EEG) showed electrical activity consisting of short-interval triphasic complexes occupying most of the trace, especially in anterior regions. This was confirmed by a subsequent EEG study. Cere-

\section{KARGER}

E-Mail karger@karger.com

www.karger.com/ene (c) 2014 S. Karger AG, Base

0014-3022/14/0722-0082\$39.50/0
Dr. José Antonio Crespo-Burillo Department of Neurology Hospital Universitario Miguel Servet Isabel la Católica, 1-3, ES-50009 Zaragoza (Spain)

E-Mail josanjoseli@ hotmail.com 
brospinal fluid (CSF) tested positive for 143-3 protein. All other tests yielded negative results, including serology studies for HIV and syphilis, metabolic studies, and CSF screen (biochemistry profile, anti-onconeural antibodies, cytometry, and microbial cultures). Symptoms progressed to include myoclonic jerks in the upper limbs and akinetic mutism. Two weeks after being hospitalized the patient died of a respiratory infection.

Doctors performed an autopsy and sent samples to Instituto de Salud Carlos III to test for prion diseases. No mutations were found in the PRNP gene, which was homozygous for methionine at codon 129. Microscopic examination of the brain revealed spongiform degeneration that was predominant in the cerebellum and frontal lobes. Immunostaining results were positive for the prion protein, and neuronal loss and gliosis were observed with no amyloid plaques. These findings confirmed the diagnosis of CJD. Since the patient was a recipient of a lyophilized dura mater graft, the case has been recognized and recorded as iCJD by the National Spongiform Encephalopathy Registry at Instituto de Salud Carlos III.

\section{Discussion}

Since 1987, when the first case of dural CJD (dCJD) associated with a dural graft was published in the USA [5], more than 200 cases have been described worldwide. Most of them have been linked to Lyodura grafts, which were first marketed in 1969 by B. Braun Mesungen AG (Germany). New techniques for disinfecting, tracing, and processing tissues were later developed [2]. Since the introduction of such techniques, only a few cases have been found to be caused by other types of lyophilized dura mater grafts $[6,7]$. An exhaustive investigation was unable to determine whether or not the graft used in our patient was a Lyodura product.

More than half of these dCJD cases have been recorded in Japan [3]. The risk of developing dCJD after grafting is estimated at 1 per 500-2,000 cases, depending on the study population and the year of the graft $[8,9]$. No specific studies of this subject have been performed in Spain.

It has been suggested that the location of the dural graft might be correlated to the patient's symptoms, since the incidence of cerebellar and brainstem dysfunction is
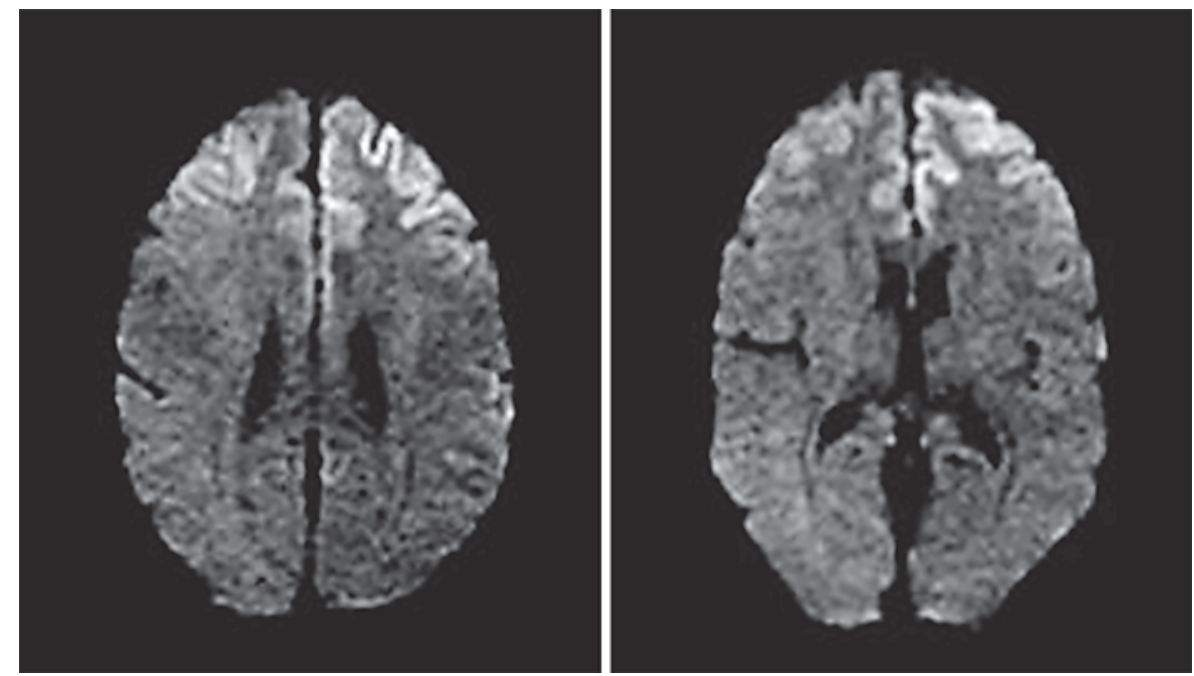

Fig. 1. Diffusion-weighted MR images showing signal intensity in cortical grey matter in in the frontal area of both hemispheres.

higher in patients with infratentorial grafts. There are no significant clinical differences regarding the development of psychiatric disorders, dementia, myoclonus, or pyramidal and extrapyramidal signs $[10,11]$. The incubation period in such cases has varied between 1.3 and 30 years (mean 12 years) [3], and reached 24 years in our patient. Although the incidence rate has declined significantly, a few cases with prolonged incubation periods are still being reported in subjects infected in the 1980 s and early 1990s [3, 11]. These cases have changed our understanding of the maximum incubation periods for CJD due to contaminated dura mater, and they remind us that we must be on the lookout even today. However, incubation periods in these cases are shorter than in those linked to human growth hormone treatment; periods of up to 42 years have been observed in the latter group [3]. MRI findings in our case were similar to those from other iCJD cases [12] and were no different from those described in the sporadic subtype [13]. The diagnostic sensitivity of 14-3-3 protein levels is lower than in sporadic CJD, but elevated levels are found in up to $75 \%$ of all iCJD cases [14]. The patient was homozygous for methionine at codon 129 of the PRNP gene. This polymorphism predisposes individuals to developing prion diseases of any type [3]. Clinical and paraclinical findings met criteria for probable CJD. Doctors therefore decided to perform an autopsy and send the samples to an official laboratory, which confirmed the diagnosis of CJD.

Despite the fact that the incidence of published cases has decreased in recent years, new iCJD cases are still likely to be recorded because of the disease's long incubation period. Thus, keeping exhaustive records of patients' medical histories and a high level of suspicion remain vital for diagnosing new cases correctly and providing epidemiological surveillance.

\section{Acknowledgment}

We thank the Research Office of the Spanish Society of Neurology for providing translation assistance.

\section{Disclosure Statement}

The authors have no conflicts of interest to disclose. 


\section{References}

1 Will RG, Alperovitch A, Poser S, et al: Descriptive epidemiology of Creutzfeldt-Jakob disease in six European countries, 1993-1995. EU Collaborative Study Group for CJD. Ann Neurol 1998;43:763-767.

-2 Brown P, Brandel JP, Preece M, Sato T: Iatrogenic Creutzfeldt-Jakob disease: the waning of an era. Neurology 2006;67:389-393.

3 Brown P, Brandel JP, Sato T, et al: Iatrogenic Creuzfeldt-Jakob disease, final assessment. Emerg Infect Dis 2012;18:901-907.

4 Instituto de Salud Carlos III (Internet). Madrid, Instituto de Salud Carlos III, 2013. Encefalopatías Espongiformes Transmisibles $\mathrm{Hu}$ manas; 1.7.2013. Cited 17.9.2013. http:// www.isciii.es/ISCIII/es/contenidos/fd-servicios-cientifico-tecnicos/fd-vigilancias-alertas/fd-enfermedades/encefalopatias-espongiformes-transmisibles-humanas.shtml.

5 Centers for Disease Control and Prevention (CDC). Update: Creutzfeldt-Jakob disease in a patient receiving a cadaveric dura mater graft. MMWR Morb Mortal Wkly Rep 1987; 36:324-325.
6 Hannah EL, Belay ED, Gambetti P, et al: Creutzfeldt-Jakob disease after receipt of a previously unimplicated brand of dura mater graft. Neurology 2001;56:1080-1083.

7 Dobbins JG, Belay ED, Malecki J, et al: Creutzfeldt-Jakob disease in a recipient of a dura mater graft processed in the USA: cause or coincidence? Neuroepidemiology 2000;19: 62-66.

8 Brooke FJ, Boyd A, Klug GM, Masters CL, Collins SJ: Lyodura use and the risk of iatrogenic Creutzfeldt-Jakob disease in Australia. Med J Aust 2004;180:177-181.

$\checkmark 9$ Centers for Disease Control and Prevention (CDC). Update: Creutzfeldt-Jakob disease associated with cadaveric dura mater grafts: Japan, 1979-2003. MMWR Morb Mortal Wkly Rep 2003;52:1179-1181.
10 Heath CA, Barker RA, Esmonde TF, et al: Dura mater-associated Creutzfeldt-Jakob disease: experience from surveillance in the UK. J Neurol Neurosurg Psychiatry 2006;77:880882.

11 Sakai K, Hamaguchi T, Noguchi-Shinohara $\mathrm{M}$, et al: Graft-related disease progression in dura mater graft-associated Creutzfeldt-Jakob disease: a cross-sectional study. BMJ Open 2013;3:e003400.

12 Kim HL, Do JY, Cho HJ, et al: Dura mater graft-associated Creutzfeldt-Jakob disease: the first case in Korea. J Korean Med Sci 2011; 26:1515-1517.

13 Zerr I, Kallenberg ZK, Summers DM, et al: Updated clinical diagnostic criteria for sporadic Creuzfeldt-Jakob disease. Brain 2009; 132:2659-2668.

14 Sánchez-Juan P, Green A, Ladogana A, et al: CSF tests in the differential diagnosis of Creutzfeldt-Jakob disease. Neurology 2006; 67:637-643. 